\title{
Spouse's participation in perinatal care: a qualitative study
}

Nahid Mehran ${ }^{1}$, Sepideh Hajian ${ }^{2 *}$, Masoumeh Simbar ${ }^{3}$ and Hamid Alavi Majd ${ }^{4}$

\begin{abstract}
Background: Pregnancy is one of the most important periods of any woman's life, wherein the support of her relatives, especially her spouse, enables her to tolerate the difficulties with good memories. However, in Iran, there are very few studies on the participation of spouses in the perinatal period. Therefore, the present study aimed to explain the concept of spouse participation in perinatal care.

Methods: This is a qualitative study that was carried out in 2018 on spouse participation in perinatal care in Qom, Iran. Purposive sampling from pregnant or postpartum women, spouses, midwifery care providers, and key informants was performed according to study inclusion criteria. Semi-structured in-depth interviews were carried out until the data saturation was met. Also, the data analysis was performed based on a conventional content analysis approach according to Graneheim \& Lundman steps using MAXQDA software (v.10). Five Guba and Lincoln criteria were applied to ensure the trustworthiness of data.
\end{abstract}

Results: Fifty-three final codes were classified into 18 sub-categories, 7 categories, and 3 themes including empathy (emotional and cognitive understanding), accountability (supporting, position management, compassion), and consequences (help improvement of family function, improvement of maternal-neonatal health).

Conclusions: Based on the findings of this study, the concept of men's participation in this period has been defined as a set of empathic and responsive behaviors that can lead to improvement of the family function and mother and baby health.

Keywords: Spouses, Caregivers, Perinatal Care, Qualitative Research

\section{Background}

Pregnancy is one of the most significant periods in every woman's life that if is accompanied by the support of close relatives, especially their spouses, it will be easier to bear the difficulties [1]. The issue of spouses' participation in women's reproductive health care was addressed in the International Conference on Population and Development (ICPD) and the Fourth World Conference on Women [2,3]. Despite the undeniable

\footnotetext{
* Correspondence: s.hajian@sbmu.ac.ir

${ }^{2}$ Midwifery and Reproductive Health Research Center, School of Nursing and Midwifery, Shahid Beheshti University of Medical Sciences, Tehran, Iran

Full list of author information is available at the end of the article
}

role of spouses in women's reproductive health, it has historically attracted less attention [4].

Father involvement in pregnancy and childbirth has positive outcomes such as the reduced probability of preterm delivery, low birth weight, and fetal growth restriction [5-8]. Also, the men's presence in maternal and child care opens up a new opportunity for health care providers to educate future fathers, and assist them in their health enhancement [9]. However, in some societies, the men's awareness of their role in supporting their pregnant wives has been ignored and it results in direct outcomes (such as improper compatibility with the perinatal period and decreasing the father's supportive role after birth [10-13]) and indirect negative impacts (such as educational, behavioral and developmental problems of children in terms of

(c) The Author(s). 2020 Open Access This article is licensed under a Creative Commons Attribution 4.0 International License, which permits use, sharing, adaptation, distribution and reproduction in any medium or format, as long as you give appropriate credit to the original author(s) and the source, provide a link to the Creative Commons licence, and indicate if changes were made. The images or other third party material in this article are included in the article's Creative Commons licence, unless indicated otherwise in a credit line to the material. If material is not included in the article's Creative Commons licence and your intended use is not permitted by statutory regulation or exceeds the permitted use, you will need to obtain permission directly from the copyright holder. To view a copy of this licence, visit http://creativecommons.org/licenses/by/4.0/. The Creative Commons Public Domain Dedication waiver (http://creativecommons.org/publicdomain/zero/1.0/) applies to the data made available in this article, unless otherwise stated in a credit line to the data. 
the reduction of father-child relationships, decrease in social support, and increased level of maternal stress hormones [14]). In many cases, although men are interested in engaging in pregnancy and childbirth, lack of incentives and restrictions and obstacles prevent their active participation [15]. Therefore, it seems necessary to strengthen the facilitator and remove the barriers as far as possible to increase the participation of men in perinatal care.

In Iran, in some health centers, spouses can attend in one to two sessions of eight-session classes for delivery preparation. However, there is a limited number of these training centers, and the proposed approach is not properly implemented and monitored [16]. In Qom city, Iran, there are limitations on the presence of men in midwifery units in most public centers. On the other hand, in Iran, especially in Qom, few studies have scrutinized the self-concept of spouse participation in maternal care. Since, the prioritization of mothers' health and efforts to provide the desired services is a guarantee of the health of the family and the future generation and the provision of high-quality health services for pregnant women, as vulnerable groups, requires considering the roles and the experiences of women, men, and other practitioners, this qualitative study aims to explore the concept of spouse participation in perinatal care.

\section{Methods}

\section{Study design}

This qualitative research used a content analysis approach.

\section{Settings, sample, and recruitment}

The participants included five women who were pregnant or had recent delivery, seven spouses, and nine key informants (deputy health managers and policymakers) of Qom city. Qom city is located $170 \mathrm{~km}$ to the south Tehran, Iran, with an area of $285 \mathrm{~km}^{2}$ and a population of 1,200,000 people. In Qom, due to religious conditions, there are different ethnicities from different parts of Iran and a few countries around the world.

The participants were selected through purposive sampling. The key informants were from public centers and the pregnant women and newly mothers and spouses were accessed through perinatal clinic or postpartum ward of Izadi hospital (one of the public hospital of Qom city). The inclusion criteria for pregnant or postpartum women (from one week to six months after delivery) and spouses consisted of the willingness to participate in this study, being Iranian, the ability to understand and express their experiences into Persian. Also, at least one year of working in midwifery- related units was added to the above criteria for caregivers and key informants. The exclusion criteria included the reluctance to take part in interviews and the withdrawal from participating in the study; however, no participant refused to be interviewed. The demographic characteristics of the participants are listed in Tables 1 and 2.

All of the interviews were conducted by the first author of this article (N.M) as a faculty member and $\mathrm{Ph} . \mathrm{D}$. student majoring in reproductive health with enough experience of qualitative research. Her main work's experience has been taking care of pregnant mothers in public health centers in Qom. All of the steps for data recording and data analysis were taken under the supervision of the corresponding author (S.H) as a faculty member and Ph.D. in reproductive health with several years of qualitative research.

\section{Data collection}

Data collection of this study was carried out between March and July 2018. At first, the needed permissions

Table 1 The pregnant/ postpartum women and spouses' demographic characteristics

\begin{tabular}{|c|c|c|c|}
\hline \multicolumn{4}{|l|}{ Variable } \\
\hline Age mean (years) & \multicolumn{2}{|c|}{$\begin{array}{l}\text { pregnant/ postpartum } \\
\text { woman }\end{array}$} & 34.7 \\
\hline & \multicolumn{2}{|c|}{ spouse } & 42.8 \\
\hline Age range (years) & & & $29-60$ \\
\hline \multirow[t]{4}{*}{ Age group } & \multirow{2}{*}{$\begin{array}{l}\text { pregnant/ } \\
\text { postpartum } \\
\text { woman }\end{array}$} & $<35$ years & 2 \\
\hline & & $\geq 35$ years & 3 \\
\hline & \multirow[t]{2}{*}{ spouse } & $<35$ years & 2 \\
\hline & & $\geq 35$ years & 5 \\
\hline \multirow[t]{6}{*}{ Occupational status } & \multirow{3}{*}{$\begin{array}{l}\text { pregnant/ } \\
\text { postpartum } \\
\text { woman }\end{array}$} & housewife & 1 \\
\hline & & employee & 4 \\
\hline & & Self-employment & 0 \\
\hline & \multirow[t]{3}{*}{ spouse } & housewife & 0 \\
\hline & & employee & 4 \\
\hline & & Self-employment & 3 \\
\hline \multirow[t]{6}{*}{ Educational level } & \multirow{3}{*}{$\begin{array}{l}\text { pregnant/ } \\
\text { postpartum } \\
\text { woman }\end{array}$} & Diploma or less & 2 \\
\hline & & Bachelor's degree & 2 \\
\hline & & $\begin{array}{l}\text { Master's degree or } \\
\text { higher }\end{array}$ & 1 \\
\hline & \multirow[t]{3}{*}{ spouse } & Diploma or less & 1 \\
\hline & & Bachelor's degree & 5 \\
\hline & & $\begin{array}{l}\text { Master's degree or } \\
\text { higher }\end{array}$ & 1 \\
\hline \multirow[t]{8}{*}{ Number of children } & \multirow{4}{*}{$\begin{array}{l}\text { pregnant/ } \\
\text { postpartum } \\
\text { woman }\end{array}$} & 0 & 3 \\
\hline & & 1 & 2 \\
\hline & & 2 & 0 \\
\hline & & 3 & 0 \\
\hline & \multirow[t]{4}{*}{ spouse } & 0 & 1 \\
\hline & & 1 & 1 \\
\hline & & 2 & 2 \\
\hline & & 3 & 3 \\
\hline
\end{tabular}


Table 2 The key informants' demographic characteristics

\begin{tabular}{|c|c|c|}
\hline \multicolumn{3}{|l|}{ Variable } \\
\hline \multicolumn{2}{|l|}{ Age mean (years) } & 38.3 \\
\hline \multicolumn{2}{|l|}{ Age range (years) } & $33-44$ years \\
\hline \multirow[t]{2}{*}{ Age group } & $<35$ years & 2 \\
\hline & $\geqq 35$ years & 7 \\
\hline \multirow{3}{*}{$\begin{array}{l}\text { Number of } \\
\text { children }\end{array}$} & 0 & 4 \\
\hline & 1 & 2 \\
\hline & 2 & 3 \\
\hline \multirow[t]{3}{*}{ Educational level } & Bachelor's degree & 5 \\
\hline & Master's degree & 3 \\
\hline & $\mathrm{PhD}$ & 1 \\
\hline \multirow[t]{6}{*}{ Field of Study } & Midwifery & 3 \\
\hline & Health Education & 1 \\
\hline & Midwifery education & 2 \\
\hline & Reproductive health & 1 \\
\hline & Culture and communication & 1 \\
\hline & History & 1 \\
\hline \multirow[t]{6}{*}{ Job } & Midwife & 2 \\
\hline & Faculty member & 2 \\
\hline & cleric & 2 \\
\hline & $\begin{array}{l}\text { Head of Department of Maternal } \\
\text { Health }\end{array}$ & 1 \\
\hline & Expert of Family Health Department & 1 \\
\hline & Teacher of birth preparation classes & 1 \\
\hline \multirow[t]{6}{*}{ Working place } & Labor and Delivery Room (LDR) & 2 \\
\hline & $\begin{array}{l}\text { Maternal and Child Health Center } \\
\text { (MCHC) }\end{array}$ & 1 \\
\hline & Provincial Mothers Health Office & 1 \\
\hline & $\begin{array}{l}\text { Maternal Health Department of } \\
\text { the Ministry of Health }\end{array}$ & 1 \\
\hline & School of Nursing and midwifery & 2 \\
\hline & Clerical Seminary & 2 \\
\hline \multirow{3}{*}{$\begin{array}{l}\text { Work experience } \\
\text { (years) }\end{array}$} & $<10$ & 4 \\
\hline & $10-20$ & 2 \\
\hline & $>20$ & 3 \\
\hline
\end{tabular}

from the Deputy Chancellor of the Shahid Beheshti University of Medical Sciences and Deputy of Research of Qom University of Medical Sciences and voluntary verbal informed consent from participants were obtained, and the participants were selected according to the inclusion criteria. Prior to study commencement, the researcher explained the present study for participants to ensure their willingness to participate in the study and gave them face-to-face in-depth interviews either individually or pair wisely (depending on the desire of participants). Initially, one pilot interview was conducted, which was not analyzed, but it helped design the interview guide. The semi-structured questions of the interview were formulated by reviewing the literature and based on the experience of the author. Interviews began with an open question, such as "What is your perception of a spouse's participation in prenatal, childbirth, and postnatal period? Please explain." Then, as the interviews continued, more detailed questions were asked, such as "Do you have any experience in this regard? If yes, how was it?", "In your opinion, how much can a spouse's participation be effective during pregnancy, childbirth process, or postpartum period?" etc. (see Table 3). The interviews were recorded using a tape recorder and then transcribed at the right time to document the data. During the interviews, observations and field note method was implemented and non-verbal data

Table 3 Interview guide during the face-to-face interviews with participants

Trigger question of pregnant/postpartum women and spouses and key informants:

1. What is the meaning of spouse's participation in prenatal period, in your mind?

2. What is the meaning of spouse's participation in childbirth period (since beginning the labor pain until discharge of hospital after birth), in your mind?

3. What is the meaning of spouse's participation in postnatal period, in your mind?

Continue questions:

A. Continue questions related to pregnant/postpartum women:

1. Do you have any experience with your spouse in your past or current pregnancy or delivery?

4. In your opinion, how was this experience?

5. In your opinion, how much can your spouse's participation be effective during pregnancy, childbirth or after it?

6. In your opinion, what does your spouse need to increase his participation with you, during this period?

7. In your opinion, what are the current obstacles for your spouse's participation during perinatal period?

8. In your opinion, which factors can increase your spouse's participation during perinatal period?

B- Continue questions related to spouses:

1. Do you have any experience of participation with your wife in past or current pregnancy or delivery?

2. In your opinion, how was this experience?

3. In your opinion, how much can your participation be effective during pregnancy, birth process or postpartum?

4. In your opinion, what do you need to increase your participation during this period?

5. In your opinion, what are the current obstacles for husband's participation during this period?

6. In your opinion, which factors increase husband's participation in this period?

\section{Continue questions related to key informants:}

1. Do you have any experience with spouse' participation in perinatal period?

2. In your opinion, how was this experience?

3. According to your job experiences, how much can spouse's participation be effective during perinatal period?

4. According to your job experiences, what do husbands need to increase their participation with their wife during this period?

5. According to your job experiences, what are the current obstacles for spouses' participation during this period?

6. According to your job experiences, which factors increase spouses' participation in this period? 
such as tone and gestures were recorded. The interviews lasted for 30-90 $\mathrm{min}$ (average of $55 \mathrm{~min}$ ) in the Izadi hospital (one of Qom's public hospitals, located almost in the center of the city with many clients) and participants' homes - or the places where the participants felt more comfortable.

Key informants of this study were the deputy health managers at the Qom University of Medical Sciences and policymakers from the Ministry of Health and Medical Education. The data collection of key informants was similar to the former process used for spouses. In this respect, they were semi- structurally interviewed deeply with the same open questions for 45-90 min (average of $60 \mathrm{~min}$ ) in hospitals, health centers, or other places. The questions guide of interviews is shown in Table 3.

The interviews with the participants continued until the occurrence of data saturation, i.e., new data entering the study did not alter the available classification and not suggest the creation of a new class [17]. Data saturation of this study was obtained in the 15th interview. Nevertheless, six more interviews were conducted to ensure the reliability of data collection. Besides, no interviews needed to be repeated.

\section{Data analysis}

The data were analyzed using the conventional content analysis method, according to Graneheim \& Lundman [18]. Accordingly, at the end of each Persian-based interview, all notes and the audio file of the interviews were word-by-word typed and handwritten. Then the typed texts were read several times to get an overview of their contents. Based on the inductive method, semantic units and initial codes were determined, the similar codes were embedded in more sub-categories, and the categories and themes appeared [18]. For better data management, after recording on the paper, MAXQDA v.10 was used simultaneously with each interview. MAXQDA is a software program designed for qualitative and mixed methods data, multimedia and text analysis. The program's central elements are the systematic assignment ("coding") of data segments (text, tables, media ...) to major themes ("codes") and the possibility of taking notes of references, ideas, etc. directly in the text ("memos") (https://www.maxqda.com/ how-to-analyse-qualitative-data). The analysis stages are shown in Fig. 1.

\section{Rigor and trustworthiness}

The five Guba and Lincoln criteria (including credibility, dependability, transferability, conformability, and authenticity) were applied to ensure the trustworthiness of data [19]. To increase the credibility of the data, "searching for disconfirming evidence" was done to extract the data that challenged the conceptualization and descriptive theory extracted from the data. Therefore, it was attempted to make a comprehensive sampling of people who could have opposing views via selecting a variety of participants with different characteristics (age, educational level, occupation, number of pregnancies, live children, and so forth). Also, the codes were independently reviewed by other members of the research team. Besides, the prolonged engagement of the researcher was noticed as well.

The interviews were carefully recorded and written to verify the dependability of the data. Also, during writing the report, it was cited to participants' conversations. Also, the study was reviewed by the supervisors and experts, and some interviews were randomly re-coded over the next two weeks to ensure coding consistency.

A rich and detailed description of the research process was provided to increase the transferability so that readers of the report can understand the steps and interactions of the study.

The opinions of three experts in qualitative research and reproductive health were also regarded to increase the conformability of the data.

The researchers made efforts to select the appropriate people for interviews and provide a rich and detailed description to increase the authenticity of the data [20].

\section{Ethical considerations}

The Ethical approval of this research was received from the Ethics Committee of Shahid Beheshti University of Medical Sciences (ethical approval code: IR. SBMU.PHNM.1394.284). In this regard, the following considerations were incorporated in the present study: obtaining the voluntary verbal informed consent, preservation of anonymity, paying attention to the willingness of participants to choose the location and time of the interview, charging no fee to the participants, preservation of confidentiality, and recognizing the right of participants to leave the study at any time.

\section{Results}

At the end of the interview and data saturation, 1856 initial codes were extracted. Because many of the resulting codes were similar, the same codes were merged. At last, 53 final codes were classified in 18 sub-categories, 7 categories, and 3 themes. The final themes were empathy, accountability, and consequences (Table 4).

\section{Empathy}

Men should understand their wives, either emotionally or cognitively. This theme contained 2 categories and 6 sub-categories.

\section{Emotional understanding}

Most participants believed that spouses should pay attention to their wives, encourage them to be hopeful 
At the end of each interview, all notes and audio of the interviews, were typed word-by-word and handwritten and then were imported in MAXQDA.

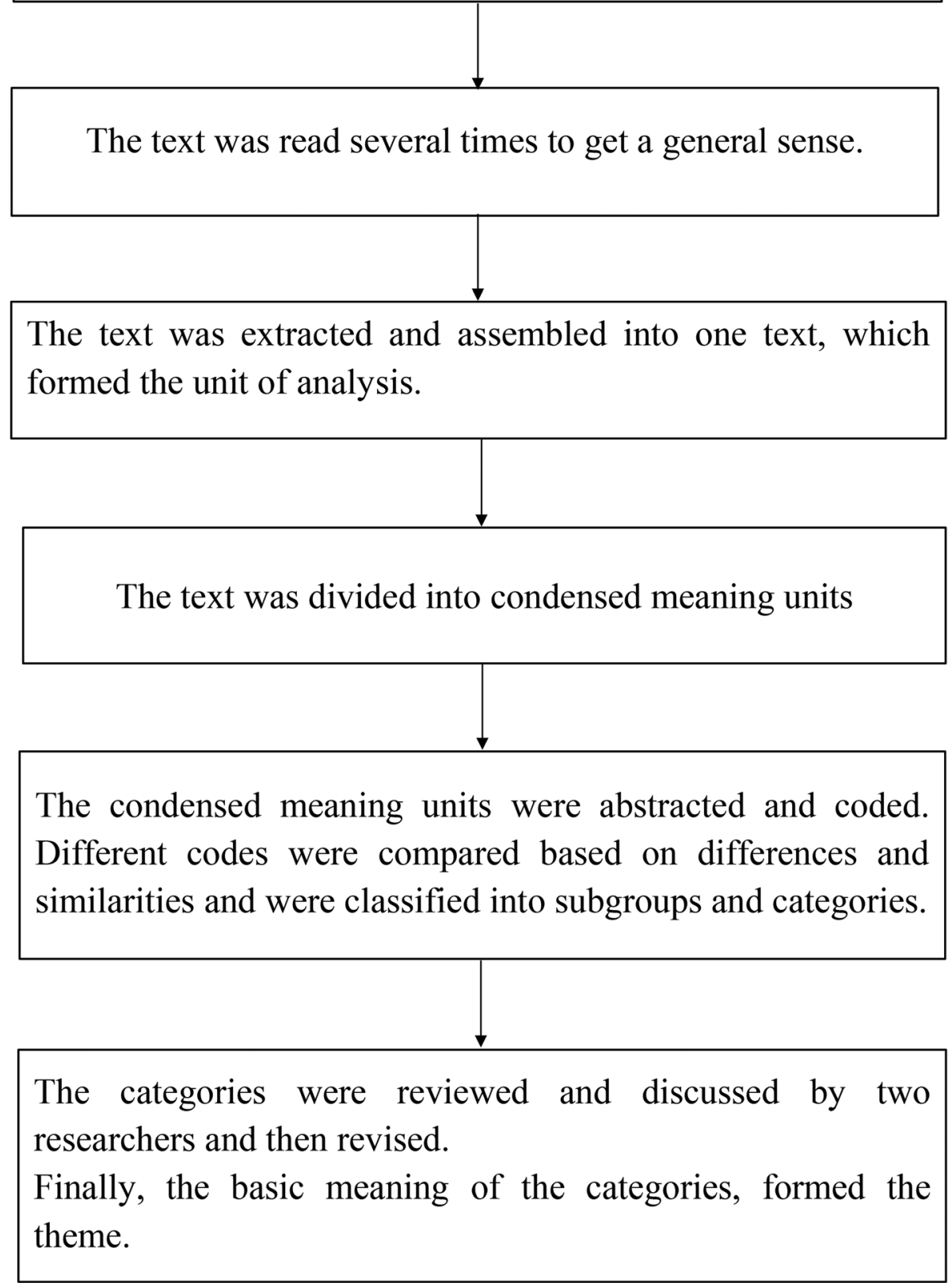

Fig. 1 Flow chart of Graneheim \& Lundman analysis (2004)

about the future, and, if necessary, make sacrifices. This category had three sub-categories.

\section{Empathetic attention}

Some participants stated that a spouse should understand the new situation of his wife during pregnancy, childbirth, and the postpartum period. Also, he should be mindful of the needs and desires of his wife and children to be able to fulfill them.

"I can understand that in the situation that she is in, she may sometimes be psychologically 
Table 4 Results of data analysis

\begin{tabular}{|c|c|c|c|}
\hline Code & Sub-category & Category & Theme \\
\hline Understand the situation & \multirow[t]{5}{*}{ Empathetic attention } & \multirow[t]{12}{*}{ Emotional understanding } & \multirow[t]{19}{*}{ empathy } \\
\hline Pay attention to the needs of the spouse and child & & & \\
\hline Control of feelings and emotions & & & \\
\hline Follow up care & & & \\
\hline Staying in empathic situations & & & \\
\hline Receive the feelings of the wife & \multirow{4}{*}{$\begin{array}{l}\text { Encouraging and } \\
\text { making hope }\end{array}$} & & \\
\hline $\begin{array}{l}\text { Displaying enthusiasm and proper feedback to the } \\
\text { spouse }\end{array}$ & & & \\
\hline Induction of faith & & & \\
\hline Reassuring & & & \\
\hline Compatibility with spouse position & \multirow[t]{3}{*}{ sacrifice } & & \\
\hline Reduce expectations and demands & & & \\
\hline Resiliency Exercise & & & \\
\hline Pre-pregnancy preparation & \multirow[t]{3}{*}{ Readiness } & \multirow[t]{7}{*}{ Cognitive understanding } & \\
\hline Pregnancy Preparation & & & \\
\hline Preparations during and after childbirth & & & \\
\hline Commitment & \multirow[t]{2}{*}{ Responsibility } & & \\
\hline Lack of deposit of responsibility to others & & & \\
\hline Trying to eliminate negative beliefs & \multirow[t]{2}{*}{ Reforming Attitudes } & & \\
\hline Creating positive beliefs & & & \\
\hline Participation in household chores & Tangible support & supporting & accour \\
\hline
\end{tabular}

Participation in the care of children

Material support

Trying to get information related to the situation

Information support

Applying the correct information in related situations

Planning before pregnancy

Planning

Position management

Planning for birthday

Managing the exposure to unexpected situations

Creating balance between indoors and outdoors

Tension management

Positive interventions in risky situations

Proper interaction

Compassion

Action to reduce the spouse's suffering and worries

Active participation in prenatal care

Dynamic presence

Accompany during childbirth

Active participation in postpartum care

Intellectual intimacy

Intimacy

Help improve family function

consequences

Sexual intimacy

Emotional intimacy

Timely intimacy

Spiritual intimacy

Psycho-emotional security

Security

Economic security

Communication security

Flexibility 
Table 4 Results of data analysis (Continued)

\begin{tabular}{lll}
\hline Code & Sub-category & Category \\
\hline Correlation & Respect & \\
Maintaining the dignity in the family & \\
Maintaining the social position & Maternal health & \\
Self-esteem & \\
Mental health & Improve maternal-neonatal health \\
Physical health & Neonatal health \\
Social health & \\
Secure attachment & \\
Desirable evolution & \\
Desirable growth &
\end{tabular}

disruptive, speak up, and get offended. I should understand her position." (Participant No.7, spouse, group $\geqq 35$ years).

"Not to tell me, the others or my wife want to tell me to do it. I myself must understand what is better to do." (Participant NO.10, key informant, group $\geqq$ 35 years).

Some participants believed that a spouse should be able to control his feelings and emotions in this period and should not transfer them to his wife. He should be mindful of midwifery care of his wife during pregnancy, childbirth, and the postpartum period and follow it up with more attention. He should occasionally attend cares, meetings, classes, and maternity programs to better understand his wife.

\section{Encouraging and giving hope}

Some participants believed that a spouse should show his empathetic attention to the wife by asking for her condition, whether through in-person speaking or by telephone or from a person accompanying his wife.

"When she is admitted to hospital, he should be in regular contact with her" (Participant NO.13,

Female, key informant, group $\geqq 35$ years).

Spouses should be able to respond appropriately to the wife's feelings and behaviors during this period, encourage her, and give her hope by showing his enthusiasm for the birth of the child. Some participants referred to the role of a spouse in restoring the wife's faith through spiritual conversations.

"Whenever I said to him: "I'm worried," He said: "Trust in God," and this phrase pleased me" (Participant NO.12, Pregnant woman, group $\geqq 35$ years).

\section{Sacrifice}

Some participants believed that a spouse should adapt himself to the wife's conditions until this period ends well as a good memory in her mind. Also, he should not have the same previous expectations in pregnancy and, even more importantly, in the postpartum period. He should lower expectations and practice to raise his tolerance towards the temporal changes of his wife's behaviors in this period.

"I had a bad nausea, so I even hated smells, even my husband's smell. He was very cooperative with me." (Participant No.13. female, key informant, group $\geqq 35$ years).

\section{Cognitive understanding}

From the viewpoint of most participants, spouses should logically understand their wives, be accountable, and have a positive attitude towards pregnancy and postpartum periods. This category contained three sub-categories of readiness, accountability, and reforming attitudes.

\section{Readiness}

Some participants believed that when a wife and her spouse decide to have a baby, the spouse needs to get ready to start the fatherhood process. He should increase his information, get familiar with the signs of risky situations, and handle the required affairs. Moreover, at the end of pregnancy, he should be prepared for the birthing of a new family member.

Some key informants stated that the responsibilities of spouses do not merely culminate with the childbirth process and hospitalization of their wives, but rather they should show their empathy by the presence at the hospital and fulfillment of the needed actions for delivery and discharge of his wife and child from the hospital.

"If men can attend prenatal classes, they will have some awareness of what they should do when they 
are at home, when their wife has problems" (Participant N0.1, Spouse, group $\geqq 35$ years).

"It is necessary to provide the necessary conditions for the return of his wife to home. Perhaps one of the things that worries the ladies to go back to the home is that they face a cluttered house when they return home" (Participant NO.5, Female, key informant, group $\geqq 35$ years).

\section{Responsibility}

Some participants said that a spouse should be familiar with his duties and responsibilities during this period. $\mathrm{He}$ should not expect others to take on his responsibilities.

"This is not rational that I put everything on my wife's shoulder" (participation NO.3, Spouse, group $\geqq$ 35 years).

"He should not take his responsibilities off on other women's shoulders, although it's possible that they are tired because of making meals or hosting the guests." (Participant NO.12, male, key informant, group $\geqq 35$ years).

\section{Reforming Attitudes}

Some participants acknowledged having positive attitudes towards pregnancy, childbirth, and postpartum as one of the responsibilities of spouses during this period and believed that they should think of pregnancy and childbirth as a mutual role. If they have a positive attitude and be familiar with the problems of this period, they will not find their wives' behavioral changes spoiling. Also, they should try to correct the negative and false believes of the people around them.

"Even about the false words that people around tell her, for example, recommending a herbal medicine for curing newborn jaundice or colic, he should not let his wife take that wrong herbal medicine"

(Participant NO.4, female, key informant, group $\geqq$ 35 years).

\section{Accountability}

Most participants believed that, during this period, in addition to emotional and cognitive understanding, spouses should support their wives and show their compassion through proper management and correct planning. In this regard, they should also take the needed actions to reduce their wives' discomfort and handle dangerous situations. This theme contained 3 categories and 6 sub-categories.

\section{Supporting}

Some participants believed that a spouse should support his wife in home care, taking care of newborn children and other children, and financial affairs. He should also increase information and awareness and acquire the ability to use the information properly. This category contains two sub-categories, namely tangible support and information support.

Tangible support All participants believed that spouses should be involved in housework, especially those activities difficult to do for a pregnant woman. They said that the participation of spouses in the postpartum period is more important than ever before due to the addition of newborn care to her previous activities.

"After childbirth, we should help in all aspects, especially in the first 30-40 days, which is very difficult." (Participant NO.1, Spouse, group $\geqq 35$ years).

Some participants acknowledged the financial support of wife and children and meeting the living expenses and material needs as spouse's duties.

Information support Some participants emphasized the necessity of men's awareness of pregnancy, childbirth, and the postpartum period as a spouse's duties and complained of insufficient awareness in this area. Also, men should be able to use this information in appropriate situations. In other words, this higher and desirable level of participation develops after cognitive understanding, i.e., at the cognitive understanding stage, the spouses' knowledge was increased and in this stage, they utilized that learned information.

"When wife's labor pains start, her spouse can remind her, the breathing techniques since she is not focused."(Participant NO.13, female, key informant, group $\geqq 35$ years).

\section{Position management}

Proper planning for childhood and well-suited management to deal with the situations and challenges of this period were other statements made by the participants. This category contained 2 sub-categories: planning and management.

Planning Some participants believed that spouses should plan before childbearing, i.e., when they decide to have children. They identified the need to plan for a new family member's birthday as one of the spouse's responsibilities during this.

Management Some female participants said that a spouse should be able to manage unexpected situations, 
such as the sudden onset of labor pain or the occurrence of risk signs, and he should not cause the wife's discomfort. Almost all female participants believed that spouses should make a balance between indoor and outdoor activities and not prefer their jobs to the family.

"This psychologically and culturally is needed to receive the attention that "we work to live, not we live to work." Men must understand that the value of life is something rather than money." (Participant NO.17, Pregnant woman, group $<35$ years).

\section{Compassion}

Compassion is indeed an understanding of the problems, as well as having the duty to help solve the problems of ourselves or others, including key components such as altruism, kindness, and joy. In general meaning, compassion might be confused with empathy, whereas empathy is a stage before compassion (prerequisite) [21]. This category contains two sub-categories: proper interaction and dynamic presence.

Proper interaction Some key informants believed that spouses should be able to take necessary actions in dangerous situations, including dialogue and interaction with health care providers and giving them the needed guidance to manage the situation accurately.

"If she is at high risk and needs special care, $f$ (e.g., special dietary care or certain medication orders), her spouse can interact with her midwifery/doctor" (Participant NO.12, male, key informant, group $\geqq$ 35 years).

Dynamic presence Some participants stated that spouses should actively participate in prenatal care. After sending her to the care centers, the spouse should refer to the doctor/midwife, if possible, and listen to their recommendations and discuss the conditions of his wife with him/her to better meet her needs. Also, in this case, he can enjoy hearing the fetal heart.

"When I was going to receive care, he came inside, wherever allowed, and talked with my doctor."

(Participant NO.14, Female, key informant, group $<35$ years).

Although there is no possibility of active participation of spouses in childbirth process in many birth centers of our country, especially in state centers, most of the participants regretted this issue and stated that the spouse should be with his wife and give her encouragement and comfort when he is present in the labor room/operating room. If it is not possible, the spouse should be in contact with the person accompanying his wife or with her assigned midwife and informed of his wife's status. Some participants suggested that the center's conditions should provide the possibility that the spouse is the first person meeting his wife after childbirth. Also, some participants believed that spouses should also accompany their wives and newborns in postnatal care and play an active role.

"After childbirth, he should carry his baby for neonatal cares, such as thyroid screening." (Participant NO.5, Female, key informant, group $\geqq 35$ years).

\section{Consequences}

From the participants' standpoint, men's participation in perinatal care has positive outcomes, such as helping the improvement of family function and maternal/neonatal health. This theme contained two categories and six sub-categories.

\section{Help with the improvement of family function}

The participants referred to creating and enhancing intimacy, sense of security, coherence, and respect among family members as positive outcomes of spouse's participation in this period. This category had four sub-categories.

Intimacy Intimacy is the ability to develop deep relationships among couples to resolve conflicts, share the experiences, and receive a sense of internal security from the other side.

Some participants believed that spouse participation leads family members, especially couples, to interact with each other more likely through exchanging views and information. Furthermore, they will be similar in attitudes and respect the opinions of one another (intellectual intimacy). Also, the husband and wife become sexually closer (sexual intimacy), productive talks between couples increase, and they feel well emotionally, resulting in their physical and mental health (emotional Intimacy). Furthermore, the spouse spends more time with his wife and children (time intimacy), and a sincere spiritual relationship might be built between the couple as well (spiritual intimacy).

"When a woman shares her plan with her spouse, she gets more energy, can pay attention to her body, and is effective in the marital and sexual relationship. She is not tired." (Participant NO.16, female, key informant, group $<35$ years).

Security Some female participants attributed the feelings of reliance on the spouse, peace of mind of wife and children, and financial comfort to spouse's efforts to meet the financial needs of his family and better communication of family members, particularly the 
relationship between the father and his children as a consequence of spouse participation.

"If a spouse has empathy and cooperation, then the woman is warmly backed." (Participant NO.1, Spouse, group $\geqq 35$ years).

Solidarity Solidarity is the feeling of correlation, bondage, and emotional commitment that members of a family have toward one another [22]. Some participants assumed the spouse's participation as a factor for causing greater solidarity among family members. They believed that participating spouses have more flexible behaviors.

"For my second baby, I was going to bring her to the Valiasr Hospital for birthing, but she said that she wants to go to the Izadi Hospital. Although I did not agree, I brought her to the Izadi hospital."

(Participant NO.7, Spouse, group $\geqq 35$ years).

Respect Some male participants stated that if a spouse is involved in his wife's pregnancy, childbirth, and the postpartum period, she feels that she has a good situation and dignity in life. Also, it would preserve and enhance the social status of children in the future. Some participants believed that the participation of men helps maintain and increase the self-confidence of his wife and children.

"If you sometimes pull the back of your wife's neck up with your hands, your children's self-esteem will rise. In general, the child's personality mainly forms in the house." (Participant NO.1, Spouse, group $\geqq$ 35 years).

\section{Improvement of maternal-neonatal health}

In addition to improving the function of the family, the participation of spouses helps promote maternal and infant health.

Maternal health Some participants stated that the participation of spouses improves physical and mental health. Furthermore, peace of mind, the feeling of not being alone, and having secure and reliable support in the face of social problems improve the wife's social health.

"If a spouse participates at home, his wife will rest further, become healthy in a shorter time, and her stitches will get better sooner." (Participant NO.19, Spouse, group $\geqq 35$ years).

"When a woman sees her spouse at her side, doing everything to ensure her comfort, she will surely feel peace and convenience. She feels that she is backed, and there is someone that can help her in difficult circumstances, and she is not alone." (Participant NO.5, female, key informant, group $\geqq 35$ years).

Neonatal health Some participants stated that spouse participation develops a deeper emotional relationship between mother and baby and makes a secure attachment. Also, it might have a positive effect on the child's developmental process, especially on psychological and emotional development.

"If the father is involved in the caring process of his or her child ... it will certainly affect the psychological development of the children". (Participant NO.5, female, key informant, group $\geqq 35$ years).

\section{Discussion}

The present qualitative study was conducted to determine the concept of spouse's participation in perinatal care. According to the obtained results, the most important aspects of male participation in perinatal care were empathy, accountability, and consequences. As a general result, the concept of spouse's participation in prenatal care, childbirth, and postpartum period has been defined in a set of empathic and accountable behaviors towards their wives based on emotional and cognitive responses, position management, support, and compassion, that can lead to favorable consequences such as the improvement of the family function and mother and baby health.

The participants believed that a spouse should empathize with her wife and understands her during the perinatal period, emotionally and cognitively. In several studies, the necessity of loving and empathetic attention has been regarded as the most important aspect of a spouse's participation in perinatal care $[2,23,24]$. The empathy - described as the ability to supportively communicate a sensitive awareness and respect another person's feelings - helps the development of mutual trust shared understandings and, in turn, the development of a fundamental quality in any helping relationship [25]. Men and women have realized that spouses are the best providers of their wives' emotional needs in the perinatal period [26]. Ergo's study demonstrated that a spouse's emotional support is the most influential factor in decreasing postpartum depression [27].

Furthermore, participants mentioned accountability as another aspect of a spouse's participation, which is defined as being accountable to a person for the expected performance. It differs from the responsibility that is an intrinsic obligation and commitment of the individual to perform all the activities assigned to him/her [28]. The participants believed that a spouse should be accountable to his wife for his behaviors during this period. $\mathrm{He}$ 
should have proper interaction and dynamic presence, support her wife, plan and manage the hazardous and non-hazardous situations. Also, participants in a study conducted by Firouzan et al. emphasized the comprehensive participation of spouses in married life (e.g., housework, cooking, and care of children) and all decision-making during the perinatal period, which are in line with the present study. This outcome could be due to the increase in females' awareness of their rights in married life and their employment and contribution to the household economy [29]. Moreover, the participants believed that spouses should be prepared for safe delivery and unexpected events in the perinatal period. $\mathrm{He}$ should consult with his wife about the place of delivery, transport her to the hospital on time and accompany her, and stay in the delivery room or, if not allowed, in the hospital until birthing of the child. Most participants preferred spouses' physical presence in the delivery room according to the results of Kaye et al. and Simbar et al. [24, 30]. However, despite the distinct Islamic recommendations emphasizing the spouse task in supporting his wife, men are not allowed to be present in the delivery room due to some cultural beliefs, negative attitudes of staffs, inadequate personnel, heavy workload, and management structures of most hospitals, especially in public centers. This issue has highlighted the lack of spouses' participation in the delivery period in the participants' minds of this study. Fortunately, according to the Ministry of Health and Medical Education recommendations for the presence of spouses during labor in mother-friendly hospitals in recent years, most hospitals are moving towards modifying the delivery units' structures to meet this goal. However, these facilities are available in all health centers.

Helping improve the family function and maternalneonatal health caused by the participation of spouses is another area that was stated by most women and men of this study, which is consistent with the results of the study carried out by Simbar et al. and Davis et al. [24, 31]. Although the benefits of men's participation in perinatal period have been acknowledged in various studies $[29,31-35]$, it should be noted that pregnancy can be the most stressful period for men undergoing the transition to parenthood, especially in terms of own psychological reorganization [36, 37]. Their involvement in partners' pregnancy may indicate that they would like to have an important role in prospective child's development [38], but in this way, they may experience various levels of mood changes and anxiety due to fear of insensibility, past events, the transitional changes to parenting and work-related problems [39] and this can lead to mental health problems for them if not diagnosed early [40].
As a general result of this study, the concept of spouse's participation in prenatal care, childbirth, and postpartum period has been defined as a set of empathic and accountable behaviors towards their wives based on emotional and cognitive responses, position management, support, and compassion, that can lead to favorable consequences such as improvement of the family function and mother and baby health.

Since the presence of spouses in the midwifery care unit plays an important role in increasing their participation in the perinatal period, it is recommended that health care providers allow spouses, if wives wish, to attend and participate in their perinatal cares. However, this needs to change the attitude of health managers and staff towards the presence of men and improve the physical structure of health centers.

Furthermore, since some spouses do not have the proper knowledge about participation in the perinatal period, despite the desire to do that, it is suggested that health centers provide training classes in this regard, with the minimum cost, especially on holidays. Therefore, spouses taking part in these classes could participate in the prenatal period more effectively, contribute to the improvement of the health of their wives and child, and promote the health of the whole family as a result.

To our knowledge, this was the first study in Qom city that attempted to explore spouse's participation during perinatal period. There was a need for a conceptualization of male involvement in this period because it is an important concerns of women who suffer from little husbands' support. The findings are useful to them and to health policy makers and managers to programming for resolving this issue.

Another strength of this study is almost comprehensive study that the data generated from multiple respondents including pregnant or recently-delivered women, spouses and health providers and managers.

Despite the diversity of participants in this study, considering its qualitative approach, the obtained results can not be generalized to other places and cultures. However, the results may be beneficial to those willing to use the results while considering the limitations.

\section{Conclusions}

The present study was conducted to determine the concept of spouse's participation in perinatal care. Based on the findings of this study, the concept of men's participation in this period has been defined as a set of empathic and responsive behaviors towards their wives based on emotional and cognitive responsiveness, position management, support, and compassion that can lead to desirable consequences such as the improvement of the family function and mother and baby health. 


\section{Abbreviation}

ICPD: International Conference on Population and Development.

\section{Acknowledgements}

We thank the Vice-chancellor for Research of Shahid Beheshti University of Medical Sciences and Qom University of Medical Sciences for their support. Also we thank the fathers, mothers, health providers and health managers of Qom and policymakers of the Ministry of Health and Medical Education for their participation in this study.

\section{Authors' contributions}

All authors participated in various stages of study design and

implementation and also in writing the manuscript. NM drafted the first and final version of the manuscript and included the COREQ checklist for reporting this qualitative research. SH read, revised and approved the final manuscript. In addition, MS and HAM revised the manuscript. All authors approved the final version.

\section{Funding}

Funding for this study was provided by the first author.

\section{Availability of data and materials}

The datasets used and/or analyzed during the current study are available from the corresponding author on reasonable request.

\section{Ethics approval and consent to participate}

The Ethics Committee of the Shahid Beheshti University of Medical Sciences in Tehran, Iran approved the protocol of this study (code number: IR. SBMU.PHNM.1394.284). Voluntary verbal informed consent is obtained from each participant of this study after explaining the procedures by researcher. This verbal consent was witnessed by a supervisor. Procedures for obtaining informed consent were approved by the abovementioned ethics committees.

\section{Consent for publication}

Not applicable.

\section{Competing interests}

The authors declare that they have no competing interests.

\section{Author details}

'School of Nursing and Midwifery, Shahid Beheshti University of Medical Sciences, Tehran, Iran. ${ }^{2}$ Midwifery and Reproductive Health Research Center, School of Nursing and Midwifery, Shahid Beheshti University of Medical Sciences, Tehran, Iran. ${ }^{3}$ Midwifery and Reproductive Health Research Center, School of Nursing and Midwifery, Shahid Beheshti University of Medical Sciences, Tehran, Iran. ${ }^{4}$ Department of Biostatistic, School of Paramedical Sciences, Shahid Beheshti University of Medical Sciences, Tehran, Iran.

\section{Received: 14 August 2019 Accepted: 15 July 2020}

\section{Published online: 26 August 2020}

\section{References}

1. D'Aliesio L, Vellone E, Amato E, Alvaro E. The positive effects of father's attendance to labour and delivery: a quasi experimental study. Int Nurs Perspect. 2009;9:5-10.

2. UNFPA. International Conference on Population and Development Cairo. United Nation Population Fund. 1994. https://www.un.org/popin/icpd2.htm.

3. Greene ME, Mehta M, Pulerwitz J, Wulf D, Bankole A, Singh S. Involving Men in Reproductive Health: Contributes to Development. Background Paper to the Public Choices, Private Decisions: Sexual and Reproductive Health and the Millennium Development Goals. United Nation Millennium Development Project. 2004. https://www.faithtoactionetwork. org/resources/pdf

4. WHO. Programming For Male Involvement In Reproductive Health: Report of the Meeting of WHO Regional Advisers in Reproductive Health WHO/ PAHO, Washington, USA. 2002. https://www.who.int/reproductivehealth/ publications/general/WHO RHR 02 3/en/.

5. Alio A, Kornosky J, Mbah A, Marty P, Salihu H. The impact of paternal involvement on feto-infant morbidity among whites, blacks and hispanics. Matern Child Health J. 2010;14:735-41.
6. Alio A, Mbah A, Kornosky J, Wathington D, Marty P, Salihu H. Assessing the impact of paternal involvement on racial/ethnic disparities in infant mortality rates. J Community Health. 2011;36:63-8.

7. Ghosh J, Wilhelm M, Dunkel-Schetter C, Lombardi C, Ritz B. Paternal support and preterm birth, and the moderation of effects of chronic stress: a study in Los Angeles County mothers. Arch Womens Ment Health. 2010;13:327-38

8. Ngui $E$, Cortright A, Blair K. An investigation of paternity status and other factors associated with racial and ethnic disparities in birth outcomes in milwaukee, wisconsin. Matern Child Health J. 2009;13:467-78.

9. Mortazavi F, Mirzai KH. Participation of men in prenatal care: fears and hopes. PAYESH. 2011;11(1):51-63.

10. Sapkota S, Kobayashi T, Takase M. Spouses experiences of supporting their wives during childbirth in Nepal. Midwifery. 2012;28:45-51.

11. Premberg A, Carlsson G, Hellstrom AL, Berg M. First-time fathers' experiences of childbirth -A phenomenological study. Midwifery. 2011;27: $848-53$

12. Fenwick J, Bayes S, Johansson M. A qualitative investigation into the pregnancy experiences and childbirth expectations of Australian fathers to be. Sex Reprod Healthc. 2012;3:3-9.

13. Mbekenga $\mathrm{C}$, Lugina $\mathrm{H}$, Christensson $\mathrm{K}$, Olsson P. Postpartum experiences of first-time fathers in a Tanzanian suburb: a qualitative interview study. Midwifery. 2011;27:174-80.

14. Lu M, Jones C, Bond L, Wright M, Pumpuang K, Maidenberg M, Jones M, Garfeild D, Rowley D. Where is the F in $\mathrm{MCH}$ ? father involvement in african american families. Ethn Dis. 2010;20:2-61.

15. Brunson J. Confronting maternal mortality, controlling birth in Nepal: The gendered politics of receiving biomedical care at birth. Soc Sci Med. 2010; 71:1719-27.

16. Mortazavi F, Keramat A. The Study of Male Involvement in Prenatal Care in Shahroud and Sabzevar, Iran. Qom Univ Med Sci J. 2012;6(1):66-74.

17. Gustavsson B. The principles of knowledge creation: research methods in the social sciences. Cheltenham: Edward Elgar; 2007

18. Graneheim UH, Lundman B. Qualitative Content Analysis in Nursing Research: Concepts, Procedures and Measures to Achieve Trustworthiness. Nurse Educ Today. 2004:24(2):105-12.

19. Guba E, Lincoln Y. Competing paradigms in qualitative research In Denzin N, Lincoln $Y$, editors, Handbook of qualitative research; 1994.p. 105-117.

20. Polit DF, Beck CT. Essentials of Nursing Research: Appraising Evidence for Nursing Practice, Philadelphia, PA: Wolters Kluwer/Lippincott Williams \& Wilkins. 8th edition; 2014.p. 322-323.

21. McCaffrey G, McConnell S. Compassion: a critical review of peer-reviewed nursing literature. J Clin Nurs. 2015;24:19-20.

22. Jamshidi B, Razmi M, Haghigh Sh, Samani S. Relationship between family Solidarity and flexibility with dimensions of perfectionism. Iranian Journal of Psychiatry Clinical Psychology. 2008;14(2):199-205.

23. Mortazavi F, Mirzaii K. Reason of barriers to and outcomes of spouses' involvement in prenatal and intrapartum care program based on midwives' experiences: a qualitative study. AMUJ. 2012;15(60):104-15.

24. Simbar M, Nahidi F, Ramezani F, Ramezankhani A. Fathers' educational needs about perinatal care. A qualitative approach. Hakim Res J. 2009;12(2):19-31.

25. Mearns D, Thorne B. Person-centred Counselling in Action. London: Sage Publications; 2007

26. Sayakhot $\mathrm{P}$, Carolan-Olah M. Internet use by pregnant women seeking pregnancy-related information: a systematic review. BMC Pregnancy Childbirth. 2016:16:65.

27. Ergo A, Eichler R, Koblinsky M, Shah N. Strengthening health systems to improve maternal, Neonatal and child health outcomes: a framework Washington, DC: MCHIP, USAID; 2011.

28. Darvish H, Ramazanian Fahndari H. Responsibility and accountability, Office of Education and Research, University of Judicial Sciences and Administrative Services. 2018. http://www.re-prisons.ir/wp-content/ uploads/2018/09.

29. Firouzan V, Noroozi M, Mirghafourvand M, Farajzadegan. Participation of father in perinatal care: a qualitative study from the perspective of mothers, fathers, caregivers, managers and policymakers in Iran. BMC Pregnancy Childbirth. 2018:18(1):297.

30. Kaye DK, Kakaire O, Nakimuli A, Osinde MO, Mbalinda SN, Kakande N. Male involvement during pregnancy and childbirth: men's perceptions, practices and experiences during the care for women who developed childbirth 
complications in Mulago hospital, Uganda. BMC Pregnancy Childbirth. 2014; 14:54.

31. Davis J, Luchters S, Holmes W. Men and maternal and newborn health: benefits, harms, challenges and potential strategies for engaging men. Australia: Burnet Institute; 2012

32. Maycock B, Binns CW, Dhaliwal S, Tohotoa J, Hauck Y, Burns S, et al. Education and support for fathers improves breastfeeding rates: a randomized controlled trial. J Hum Lac. 2013;29(4):484-90.

33. Tohotoa J, Maycock B, Hauck YL, Howat P, Burns S, Binns CW. Dads make a difference: an exploratory study of paternal support for breastfeeding in Perth, Western Australia. Int Breastfeed J. 2009:4(1):15.

34. Cabrera NJ, Shannon JD, Tamis-Lemonda C. Fathers influence on their children's cognitive and emotional development: from toddlers to pre-K. Appl Dev Sci. 2007;11(4):208-13.

35. Panter-Brick C, Burgess A, Eggerman M, Mcallister F, Pruett K, Leckman JF. Practitioner review: engaging fathers- recommendations for a game change in parenting interventions based on a systematic review of the global evidence. J Child Psychol Psychiatry. 2014;55(11):1187-212.

36. Condon JT, Boyce P, Corkindale CJ. The first-time fathers study: a prospective study of the mental health and wellbeing of men during the transition to parenthood. Aust N Z J Psychiatry. 2004;38:56-64.

37. Genesoni L, Talladini MA. Men's psychological transition to fatherhood: An analysis of the literature 1989-2008. Birth. 2009;36:305-17.

38. Cabrera NJ, Fagan J, Farrie D. Explaining the long reach of fathers' prenatal involvement on later paternal engagement. J Marriage Fam. 2008;70:1094.

39. Steen M, Jones A, Woodworth B. Anxiety, bonding and attachment during pregnancy, the transition to parenthood and psychotherapy. Br J Midwifery. 2013;21:844-50.

40. Dunkel Schetter C, Tanner L. Anxiety, depression and stress in pregnancy: implications for mothers, children, research, and practice. Curr Opin Psychiatry. 2012;25:141-8.

\section{Publisher's Note}

Springer Nature remains neutral with regard to jurisdictional claims in published maps and institutional affiliations.

Ready to submit your research? Choose BMC and benefit from:

- fast, convenient online submission

- thorough peer review by experienced researchers in your field

- rapid publication on acceptance

- support for research data, including large and complex data types

- gold Open Access which fosters wider collaboration and increased citations

- maximum visibility for your research: over $100 \mathrm{M}$ website views per year

At $\mathrm{BMC}$, research is always in progress.

Learn more biomedcentral.com/submissions 